\title{
Study of Different Large Bodies Manufacturing Based on Combined Methods of Deformation
}

\author{
Pesin A., , , Drigun E., Pustovoytov D., ${ }^{1, b}$ Pesin I. \\ ${ }^{1}$ Nosov Magnitogorsk State Technical University, \\ 38, Lenin prospect, Magnitogorsk, 455000, Russia
}

\begin{abstract}
Metallurgy and heavy engineering construction, which are considered the most energy-intensive industries, place great focus on complex shaped thick-gage plate metal items of equipment with the wall thickness exceeding 40 $\mathrm{mm}$ and the diameter /width of up to $5000 \mathrm{~mm}$. Such items of equipment include large machine parts manufactured by means of hot plate stamping, like bodies of rotation (for example, the segment of the radial surface of converter shell, the bottom part of degassing unit, etc.) utilized as pressure-operated devices, vessels, tanks and other facilities by metallurgical, petrochemical, oil and gas, and nuclear industries. Presently known manufacturing methods of such items of equipment, for example hot stamping methods, have a number of technological problems. The proposed work is aimed at the development of innovative power-efficient, high performance methods of obtaining complex shaped large size items. The scientific novelty of the task lies within the creation and development of the theory and technology of the new methods of deformation based on the combination of the plate rolling and stamping processes as well as the combination of asymmetric rolling and plastic bending processes. Casings on two converters were produced and installed in the oxygen-converter plant. Economic effect from the installation of the developed technology based only on the combination of asymmetric rolling and plastic bending processes was more than 1 million dollars
\end{abstract}

\section{Introduction}

The key condition of economic development is the conversion to the brand new energy-efficient innovative technologies ensuring multiplier effect on the improvement of equipment productivity and the enhancement of finished product quality. Metallurgy and heavy engineering construction, which are considered the most energy-intensive industries, place great focus on complex shaped thick-gage plate metal items of equipment with the wall thickness exceeding $40 \mathrm{~mm}$ and the diameter/width of up to $4500 \mathrm{~mm}$. Such items of equipment include large machine parts manufactured by means of hot plate stamping, like bodies of rotation (for example, the segment of the radial surface of converter shell, the bottom part of degassing unit, etc.) utilized as pressure-operated devices, vessels, tanks and other facilities by metallurgical, petrochemical, oil and gas, and nuclear industries. Presently known manufacturing methods of such items of equipment, for example hot stamping methods, have a number of technological problems. They are the following: 1) significant power intensity of the processes due to the repeated heating of the piece and the extreme (at the limit of the equipment capacity) energy-power parameters of the plastic deformation process; 2) low productivity of the processes due to the multistage processing; 3) necessary utilization of expensive die bodies; 4) heavy-duty operation conditions of the large size items of equipment put special requirements to the structure and properties, however plate metal pieces have lower mechanical properties and significant variations in thickness which results in higher probability of crack formation, folding and other defects as well as reliability degradation of the finished metal structures. The above problems impair the economic feasibility of manufacturing of large size high-duty items of equipment.

In the global practice the principle method of manufacturing the large size items of equipment with the wall thickness exceeding $40 \mathrm{~mm}$ and the diameter/width of up to $4500 \mathrm{~mm}$ like bodies of rotation (for example, the segment of the radial surface of converter shell, the bottom part of degassing unit, etc.) utilized as pressure-operated devices, vessels, tanks and other facilities by metallurgical, petrochemical, oil and gas, and nuclear industries, is the hot stamping [1-2]. The main disadvantages of this method are low productivity, significant power intensity and necessary utilization of expensive die bodies.

This study presents new technologies of the combined process of asymmetric rolling and plastic bending as well as of the combined process of the plate rolling and stamping to produce parts of bulky bodies of

$\overline{\text { ppesin@bk.ru (corresponding author) }}$, ${ }^{\mathrm{b}}$ pustovoitov_den@mail.ru 
rotations. Traditionally, machine-building factories produce large-size bodies of rotations, with the help of an inefficient and rather costly process, using stamping or sheet-bending machines. These details are designed for usage as casings for various technological aggregates (converters, mixers, scrubbers, steel teeming ladles, etc.). The goal was to develop a cost-effective technology of large-size bodies of rotations production, in the conditions of thick-plate mill.

Results of numerical investigation showed the difficulty, and sometimes outright impossibility of producing the required product curvature using only thick plate vertical asymmetric rolling processes. The new operation, which ensures a plate of the required curvature, is needed. Plastic bending, performed with a special unbending roller, located behind the stand, serves as such an operation (Fig. 1) [3-10].
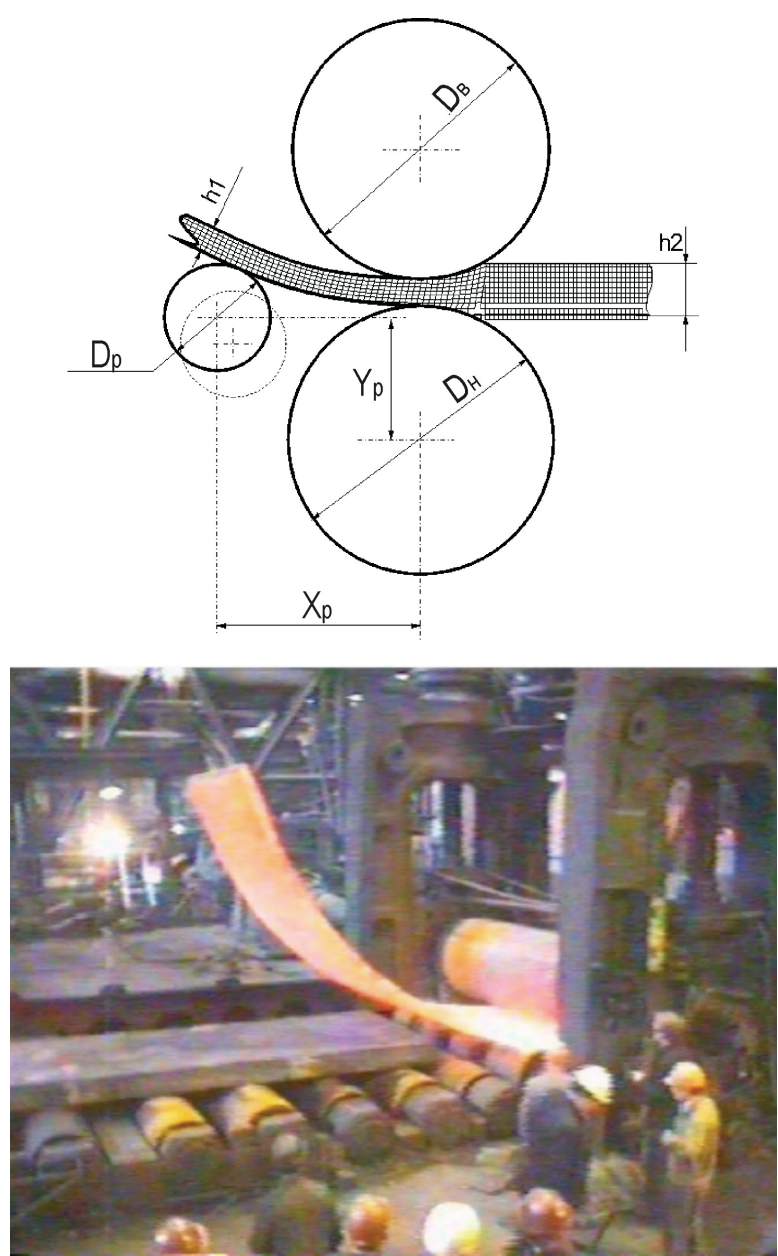

Figure1. Combined process of asymmetric rolling and plastic bending

In such conditions, a sheet with far less than required curvature (larger radius) was formed. Then, with said roller, the curvature was increased (by decreasing the radius) to the required value. Such is the combined asymmetric rolling and plastic bending process.

In order to analyze it and to develop a corresponding technology, it was necessary to conduct a theoretical and experimental investigation of this process. At the basis of the second new process lies the rolling of package. The latter consists of the upper (punch), lower (matrix) bases and situated between the blank plate is (Fig. 2).

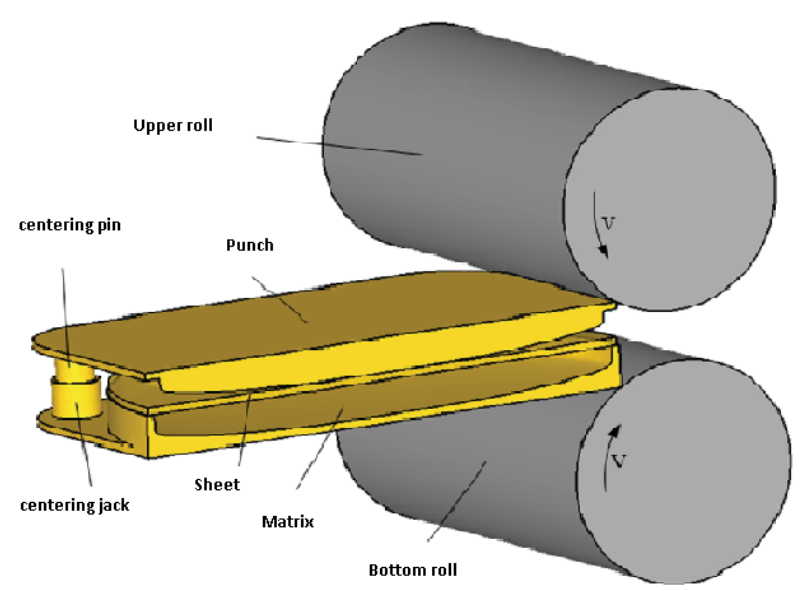

Figure 2. Scheme of the combined process of plate rolling and stamping

\section{Numerical investigation of new combined processes}

Combined process signify an integral process which combines two or more basic deformation methods (asymmetric rolling, stamping, bending), combining different deformations and stresses in one location during the production of large-scale bodies from metallic materials.

Combined process of asymmetric rolling and plastic bending can be divided into three characteristic stages: asymmetric rolling itself when the front end of metal has not reached a debending roll; additional plastic sheet bending when its front end contacts with a debending roll; a combining process of rolling and bending after the front end of a sheet has progressed beyond a debending roll. A diameter of the latter is 700 $\mathrm{mm}$.

It is important to note that at the beginning of the second stage a spasmodic increase of moment on the upper roll and a reduction on the lower roll take place (Fig. 3). The rolling moment on the upper roll increases many times, and on the lower roll - reduces and can even have a negative value. Experimental research has shown that the calculated radius of sheet bending is in excellent agreement with an actual one (deviation is not more than $\pm 7 \%$ ).

A key factor in the implementation process is the fulfillment of the conditions of capture when package rolling:

$$
\begin{array}{r}
\Delta \mathrm{H}_{\mathrm{p}} \leq 2 \mathrm{R}(1-\cos \alpha) \\
\alpha=\operatorname{arctg}(\mathrm{m})
\end{array}
$$

where $\Delta \mathrm{H}_{\mathrm{p}}$ - absolute reduction, $\mathrm{mm}, \mathrm{m}$ - index of friction, $\mathrm{R}-$ the radius of the roll, $\mathrm{mm}$. 


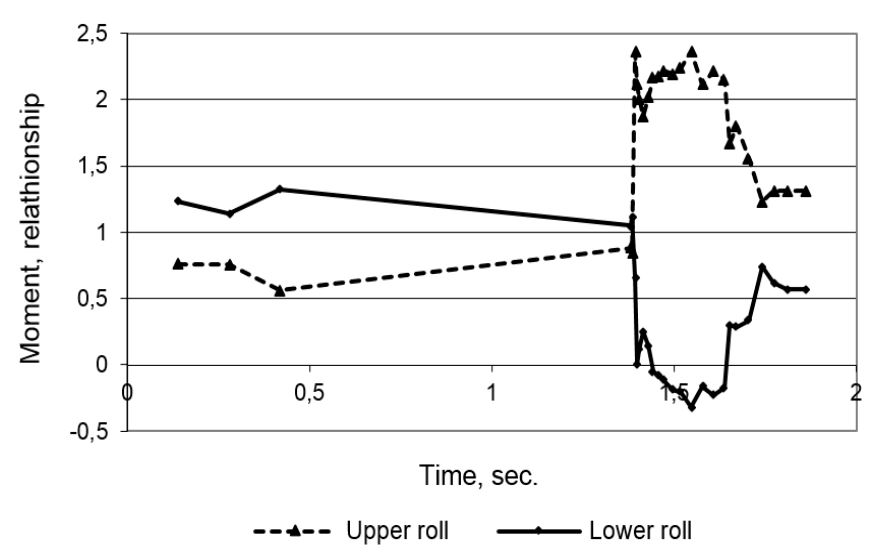

Figure 3. Rolling moment on rolls

$$
\mathrm{H}_{\mathrm{p}}=\mathrm{h}_{\mathrm{p}}+\mathrm{h}_{\mathrm{w}}+\mathrm{h}_{\mathrm{m}}
$$

where $\mathrm{H}_{\mathrm{p}}$ - the height of the package $\mathrm{h}_{\mathrm{p}}$ - the height of the punch, $\mathrm{mm} ; \mathrm{h}_{\mathrm{w}}-$ workpiece thickness, $\mathrm{mm} ; \mathrm{h}_{\mathrm{m}}$ - the height of the matrix, $\mathrm{mm}$.

The following parameters have been accepted: the diameter of the original workpiece $-2660 \mathrm{~mm}$; thickness $-40 \mathrm{~mm}$, material - steel 09G2S. The height of the finished product $-200 \mathrm{~mm}$; the temperature of the finished product $900 \mathrm{oC}$; the rolling speed $-1000 \mathrm{~mm} /$ sec; the index of friction -0.7 . The initial finite element mesh and example of the field of main stresses are shown in Fig. 4. The geometry of the final solutions are in good agreement (deviation is not more than 6\%) with the experimental results.
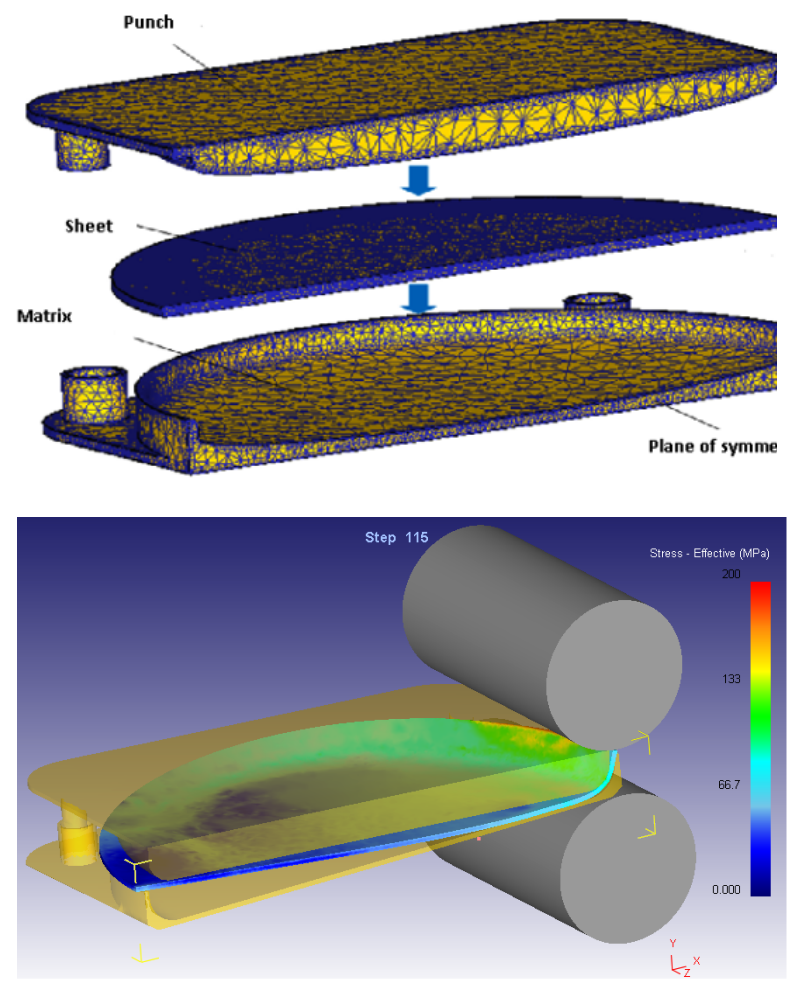

Figure 4. Simulation of the combined process of rolling and stamping

\section{Conclusions}

The new innovative power-efficient, high performance methods of obtaining complex shaped large size items have been created. This methods are based on the combination of the plate rolling and stamping processes as well as the combination of asymmetric rolling and plastic bending processes. It opens up perspectives for the development of new energy-efficient technologies of one-piece stamping large bodies obtaining analogous to rotation bodies used in metallurgical, petrochemical, gas and nuclear industries for devices operating under pressure including vessels, tanks and other industrial equipment. Casings on two converters have been produced and installed in the oxygen-converter plant. Economic effect from the installation of the developed technology based only on the combination of asymmetric rolling and plastic bending processes was more than 1 million dollars.

\section{References}

1. V.A. Demin, Development of a method of the plate stamping processes designing on the basis of forecasting of technological failure: D. Sc. Thesis. Moscow (2003) 342.

2. H. Karbasian, A.E. Tekkaya, A review on hot stamping, Journal of Materials Processing Technology. 210 (2010) 2103-2118.

3. A. Pesin, V. Salganik, E. Trahtengertz, M. Cherniahovsky, V. Rudakov, Mathematical modeling of the stress-strain state in asymmetric flattening of metal band, Journal of Materials Processing Technology. 125-126 (2002) 689-694.

4. A. Pesin, Practical results of modeling asymmetric rolling, Steel in Translation. 33 (2003) 46-49.

5. A. Pesin, New solutions on basis of non-symmetric rolling model, Stal. (2003) 66-68.

6. A. Pesin, V. Salganik, E. Drigun, D. Chikishev, Device for asymmetrical rolling metal plate, RU Patent 38646 (2004).

7. A. Pesin, V. Salganik, E. Drigun, D. Chikishev, Device for asymmetrical rolling metal plate, RU Patent 2254943 (2005).

8. A. Pesin, V. Salganik, D. Chikishev, Device for asymmetrical rolling metal plate, RU Patent 54831 (2006).

9. A. Pesin, D. Chikishev, S. Blinov, Device for measuring a radius of curvature of the cylindrical surface of large parts, RU Patent 56592 (2006).

10. A. Pesin, D. Chikishev, S. Blinov, D. Pustovoytov, Device for asymmetrical rolling metal plate, RU Patent

87649

(2009). 